\title{
Effects of Temperature and Strain Rate on Solid-/Liquid-Phase Flow Behavior of 9Cr18 Steel During Thixoforging
}

\author{
Yong-Jin Wang ${ }^{1} \cdot$ Ren-Bo Song ${ }^{1} \cdot$ Ya-Ping $\mathrm{Li}^{1} \cdot$ Qiang Chen $^{2}$
}

Received: 7 November 2016/Revised: 28 December 2016/Published online: 13 February 2017

(C) The Chinese Society for Metals and Springer-Verlag Berlin Heidelberg 2017

\begin{abstract}
A thixoforging process of the $9 \mathrm{Cr} 18$ steel was conducted in a designed setup, and a kind of multi-diameter component was fabricated. The effects of the forming temperature and the strain rate on the solid-/liquid-phase flow behavior were discussed. The results showed that functional gradient properties of the $9 \mathrm{Cr} 18$ steel could be obtained after thixoforging. Changes of microstructure along radial direction could be obtained. Solid austenite was retained after fast cooling, and the liquid film enriched in alloying elements was extruded outside to form a dendrite skin layer. As temperature increased, more molten liquid formed during thixoforging. A heterogeneous flow phenomenon was activated as free liquid channels were formed. The macro-separation of solid and liquid phases was critical for the formation of functional gradient properties. Above $1300{ }^{\circ} \mathrm{C}$, full dendrite skin layer could be formed. The strain rate affected the thixotropic property via influencing the deformation time of thixoforging. In the presence of lower strain rates, there was more time for the flow of liquid metal, which was the key to the extension of the thixotropic stage. High temperatures and low strain rates contributed to the formation of full skin layer for the designed specimen. The average thickness of skin layer for current specimen could be over $1000 \mu \mathrm{m}$ when thixoforged at $1340{ }^{\circ} \mathrm{C}$ and under a strain rate of $0.02 \mathrm{~s}^{-1}$.
\end{abstract}

\section{KEY WORDS: 9Cr18 steel; Thixoforging; Processing parameters; Functional gradient property}

\section{Introduction}

Thixoforming, as a method of semi-solid forming (SSF), is an effective near-net-shape forming technology, in which the thixotropic properties of semi-solid microstructures are fully used [1]. Since its development in the 1970s, SSF has attracted plenty of researches. SSF is considered as a promising materials forming technology due to advantages

Available online at http://link.springer.com/journal/40195

Ren-Bo Song

songrb@mater.ustb.edu.cn

1 School of Materials Science and Engineering, University of Science and Technology Beijing, Beijing 100083, China

2 Mining Design and Research Institute of Anshan Iron \& Steel Groups Corporation Anshan, Anshan 114002, China such as fewer forming steps, lower forming load and higher performance.

The production of semi-solid billets is critical for the forming process. Many methods have been proposed to prepare the spheroidal microstructure of semi-solid billets, including magneto-hydrodynamic stirring [2], cooling slope method [3], strain-induced melt activation (SIMA) and recrystallization and partial melting (RAP) [4]. SSF of light alloys such as those based on aluminum and magnesium has been taken into industrial aspects [5]. Initially, most of the components were fabricated by the thixoforming method since an automatic control was easier to fulfill. Right now, researchers are investigating new ways to industrialize the rheo-forming method with fewer process cycles [6]. Zhang et al. [7] proposed rheo-squeeze casting of AZ91-Ca alloy, improving the quality of semi-solid slurry and the mechanical properties. Bolouri et al. [8] investigated the mechanical properties of the rheo-formed A356 alloy 
through Deform-3D simulation and experimental tests. However, for high-melting alloys such as steels, thixoforming is a more practical SSF method [9]. The high semisolid temperature range (typically higher than $1250{ }^{\circ} \mathrm{C}$ ) makes it extremely difficult to integrate the semi-solid billet preparation and the forming process. Up to now, representative steels for SSF include X210CrW12, M2, 100Cr6 and SKD61. These steels normally have a larger semi-solid temperature range and a lower temperature sensitivity. Many researchers are focusing on new thixoforming technologies to overcome the difficulties connected with the SSF of steels. Becker et al. [10] studied the thixoextrusion of the C38 steel, investigating the material response toward different experimental conditions. Gu et al. [11] used confocal laser scanning microscopy to in situ study the liquid fraction of the M2 steel in the semi-solid state. Muenstermann et al. [12] designed ceramic dies to allow the semi-solid extrusion of the X210CrW12 steel under isothermal conditions.

It is commonly known that solid and liquid phases coexist during thixoforming. Kang et al. [13] pointed out that a macro-separation of solid particles and a liquid film appeared due to the outflow of the liquid film, which might lead to inhomogeneous structures. Many of the researchers attempted to avoid macro-separation and to fabricate components with uniform spheroidal microstructures to improve the mechanical properties [14]. However, macro-separation of solid and liquid phases may lead to a variation in the properties, which are based on microstructural inhomogeneity [15]. The different chemical compositions of solid and liquid phases provide foundation for the particular properties. The microstructural inhomogeneity may help to expand the application fields of the traditional materials.

The 9Cr18 (AISI: 440C) martensitic stainless steel is widely used in the fields of aerospace and marine engineering because of its good hardness, high wear and corrosion resistance. The present study is aimed at designing 9Cr18 components with inhomogeneous structure and obtaining materials with functional gradient properties. The goal is to fabricate components with a tough center and a hard surface. Here, we upgraded a Gleeble 3500 thermal mechanical machine for thixoforging process. A kind of multi-diameter shaft was fabricated in the setup, and the effect of experimental parameters on microstructure and properties was discussed. The specific flow behavior of the solid and liquid phases was clarified.

\section{Experimental Procedures}

\subsection{Cr18 Semi-solid Billet}

The material used for thixoforging is the commercial 9Cr18 (AISI: 440C) stainless steel. The chemical composition is $0.97 \mathrm{C}, 17.33 \mathrm{Cr}, 0.52 \mathrm{Si}, 0.02 \mathrm{P}, 0.005 \mathrm{~S}$, $0.10 \mathrm{Al}, 0.16 \mathrm{Ni}, 0.12 \mathrm{Co}$ and balance $\mathrm{Fe}$ (wt $\%$ ).

A $9 \mathrm{Cr} 18$ semi-solid billet was prepared by the wavelike sloping plate method [16]. As shown in Fig. 1, the microstructure exhibits spherical solid particles and a solidified liquid eutectic film. The average equivalent diameter Eq. (1) of the spherical solid grains was about $94.4 \pm 10 \mu \mathrm{m}$, and the shape factor Eq. (2) of the solid grains was about 0.80 .

$D=\frac{\sum_{1}^{N} \sqrt{4 A / \pi}}{N}$

$\mathrm{SF}=\frac{1}{\left(\sum_{1}^{\mathrm{N}} \mathrm{P}^{2} / 4 \pi \mathrm{A}\right) / \mathrm{N}}$,

where $D, \mathrm{SF}, A, N$ and $P$ are average grain size, shape factor, area, the number and perimeter of solid grains, respectively. The semi-solid billet was then machined for the subsequent thixoforging.

The solid/liquid temperature range of the $9 \mathrm{Cr} 18$ semisolid billet was determined using differential scanning calorimetry (DSC) with a heating rate of $10^{\circ} \mathrm{C} / \mathrm{min}$. According to the DSC results in Fig. $2 \mathrm{a}$, the solidus and liquidus temperatures are 1289 and $1423{ }^{\circ} \mathrm{C}$, respectively. The changes of the liquid volume fraction versus temperature are shown in Fig. 2b (Ref. [17]).

\subsection{Thixoforging Process}

\subsubsection{Design of Multi-diameter Components}

The present study is aimed at fabricating functional gradient materials with a tough center and a hard surface. The flow behavior of solid/liquid phases was used. Here, a multi-diameter shaft component was designed as shown in Fig. 3. The deformation region was designed to

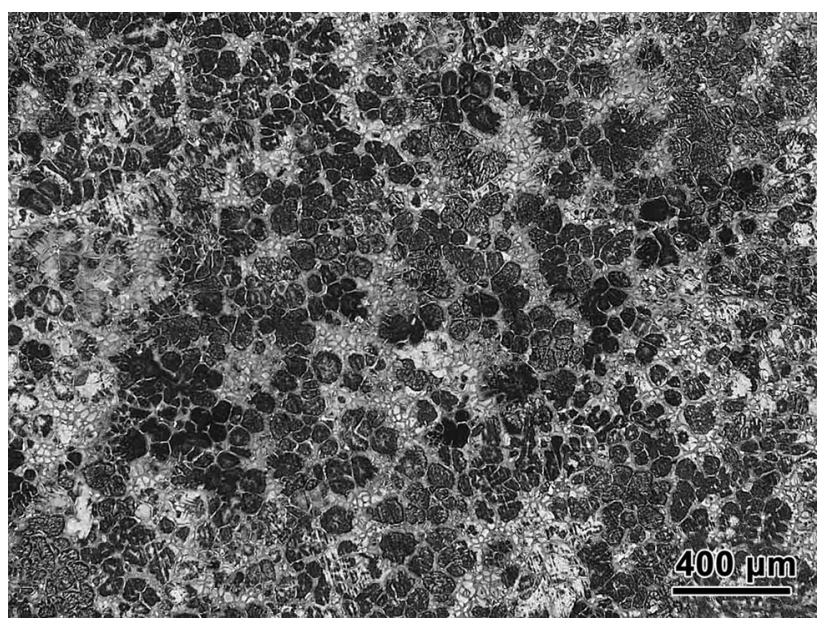

Fig. 1 Microstructure of $9 \mathrm{Cr} 18$ semi-solid billet 

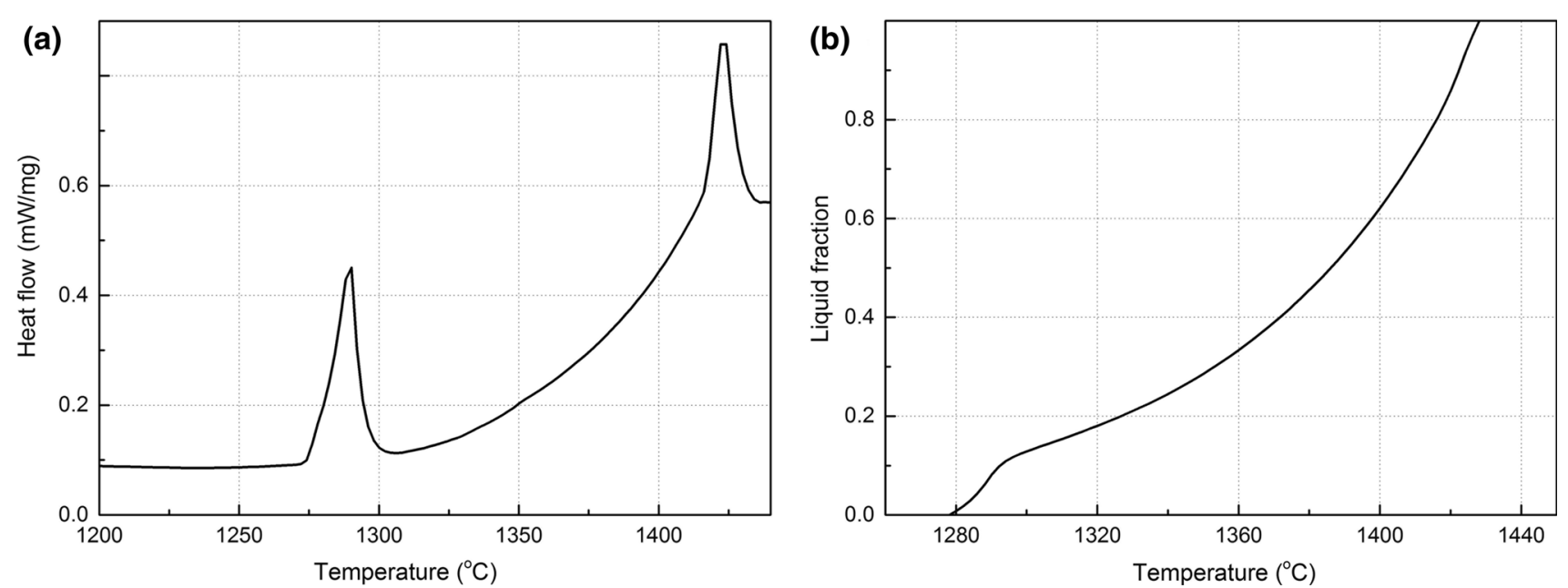

Fig. 2 DSC curves of 9Cr18 billet $\mathbf{a}$ and liquid fraction-temperature curve obtained by DSC $\mathbf{b}$
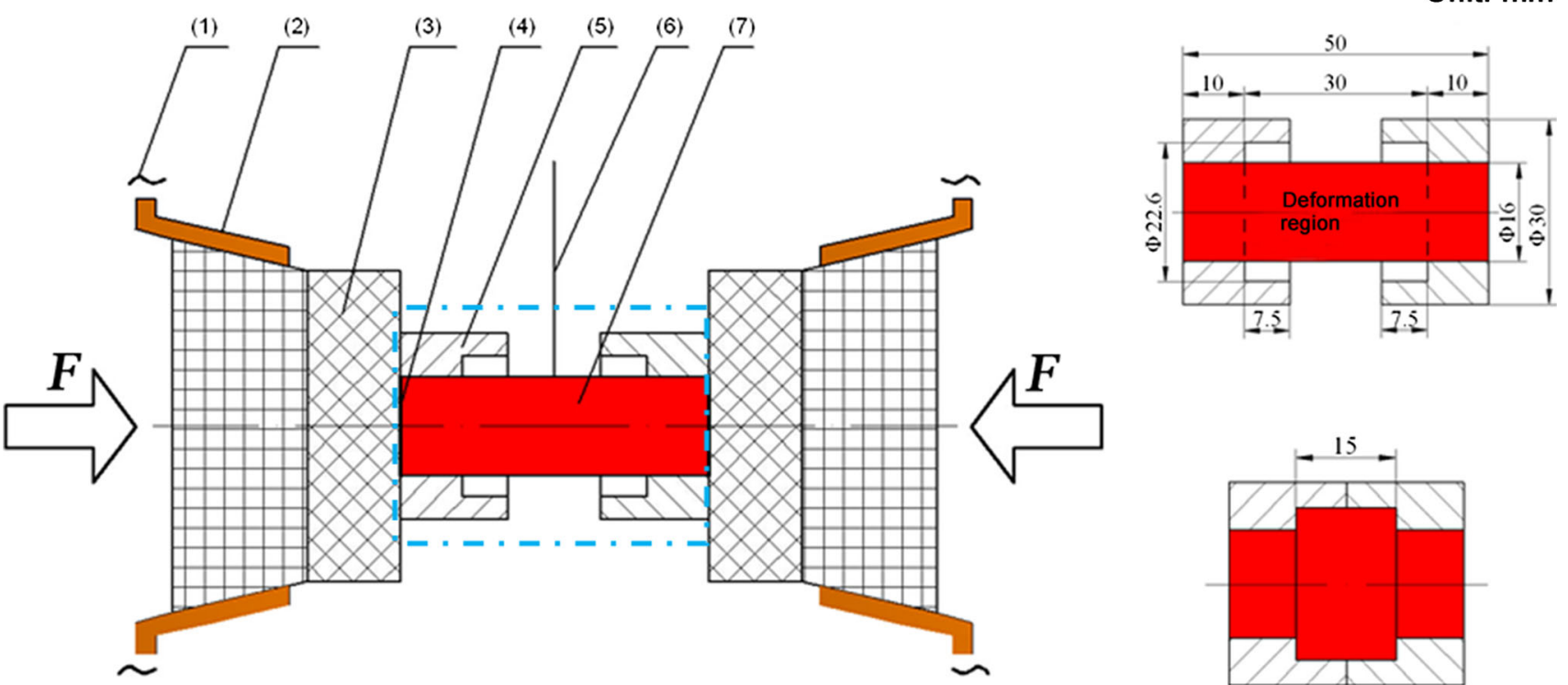

Fig. 3 Schematic illustration of the thixoforging setup. 1 AC supply; 2 copper electrode; 3 punch; 4 tantalum piece; 5 ceramic die; 6 R-type thermocouple; 7 semi-solid specimen

demonstrate the functional gradient properties after closing the two dies. The two edges were holding areas with no deformation.

\subsubsection{Thixoforging}

The thixoforging setup was re-designed from a Gleeble 3500 thermal mechanical machine. As shown in Fig. 3, the specimen (16 mm in diameter, $50 \mathrm{~mm}$ in height) and two ceramic dies were placed between two punches. The two edges of the specimen were fixed by the ceramic dies, so that the length of deformation region was of $30 \mathrm{~mm}$. Compared with previous methods [18], the heating, forming and cooling processes were all conducted in this setup and the transfer of the semi-solid billet was eliminated. After closing the two dies, a multi-diameter shaft could be fabricated. More detailed information about design of setup is given in [17].

Typically, the whole thixoforging process was conducted according to the predetermined programs shown in Fig. 4. The heating procedures are divided into two steps: (1) fast heating to $1250{ }^{\circ} \mathrm{C}$ at a rate of $10{ }^{\circ} \mathrm{C} / \mathrm{s}$ and (2) slow heating to the forming temperature at a rate of $2{ }^{\circ} \mathrm{C} / \mathrm{s}$. After holding at constant temperature for $15 \mathrm{~s}$, the forming tests were then conducted at a certain strain rate. The amount of thixoforging deformation was $15 \mathrm{~mm}$ with an actual 


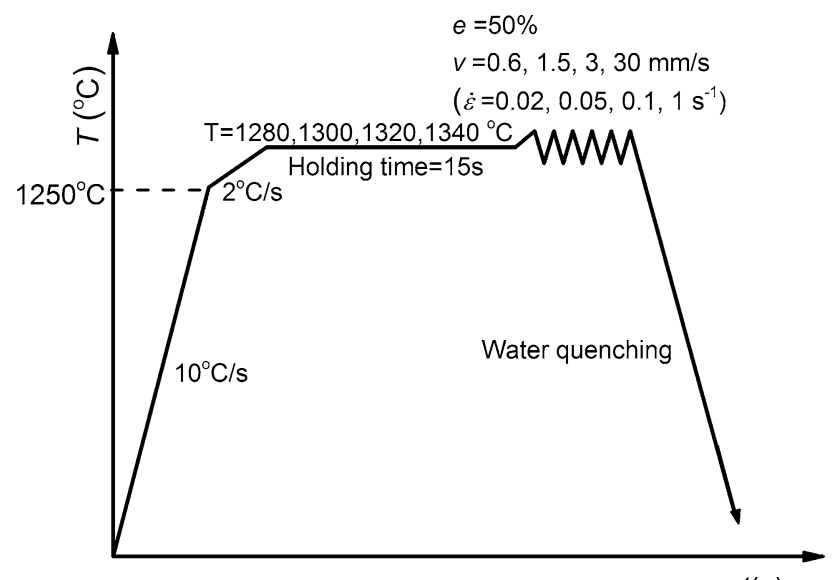

$t(\mathrm{~s})$

Fig. 4 Temperature diagram of the thixoforging process

Table 1 Experimental parameters of thixoforging

\begin{tabular}{lllll}
\hline Condition & \multicolumn{3}{l}{ Values } & \\
\hline Temperature $\left({ }^{\circ} \mathrm{C}\right)$ & 1280 & 1300 & 1320 & 1340 \\
Corresponding liquid fraction $\left(f_{1}\right)$ & 0 & $12.9 \%$ & $18.1 \%$ & $25.3 \%$ \\
Strain rate $\left(\mathrm{s}^{-1}\right)$ & 0.02 & 0.05 & 0.1 & 1 \\
Corresponding ram speed $(\mathrm{mm} / \mathrm{s})$ & 0.6 & 1.5 & 3 & 30 \\
\hline
\end{tabular}

reduction ratio of $50 \%$. Finally, water quenching was conducted after closing the dies. The load-displacement signal was saved automatically through an L-gauge component system. The experimental parameters are shown in Table 1. The forming temperature varied from 1280 to $1340{ }^{\circ} \mathrm{C}$; the strain rate varied from 0.02 to $1 \mathrm{~s}^{-1}$.

\subsection{Microstructure Observation and Hardness Tests}

Specimens at different regions of the thixoforging component were machined and etched with Vilella's reagent (1 g picric acid, $100 \mathrm{ml}$ alcohol and $15 \mathrm{ml}$ hydrochloric acid). Then, the microstructure was observed by a ZEISS Imager.M2 m optical microscopy (OM) and Zeiss EVO 18 scanning electron microscopy (SEM). Electron backscattered diffraction (EBSD: Oxford HKL Channel 5, operated at $20 \mathrm{kV}$ with step size of $0.5 \mu \mathrm{m}$ ) measurements were taken to investigate the microstructural evolution after thixoforging.

The Vickers hardness tests were carried out on a HXD1000T tester following the standard of ASTM E3842010e2. The tests were performed along the radial direction of the thixoforging specimen for the heterogeneous microstructure characterization.

\section{Results and Discussion}

\subsection{Thixoforging Specimen}

\subsubsection{Typical Microstructure Characterization}

The specimen thixoforged at $1340{ }^{\circ} \mathrm{C}$ and with a strain rate of $0.02 \mathrm{~s}^{-1}$ is shown in Fig. 5. The multi-diameter shape can be obtained after thixoforging. The semi-solid billet is able to fill the mold. A thin flash could be seen around the die closing area. The microstructure at a fixed region shows similar characterization with the semi-solid billet. The spherical solid grains and the solidified liquid film coexist. As shown in Fig. 5a, b, rare obvious microstructure

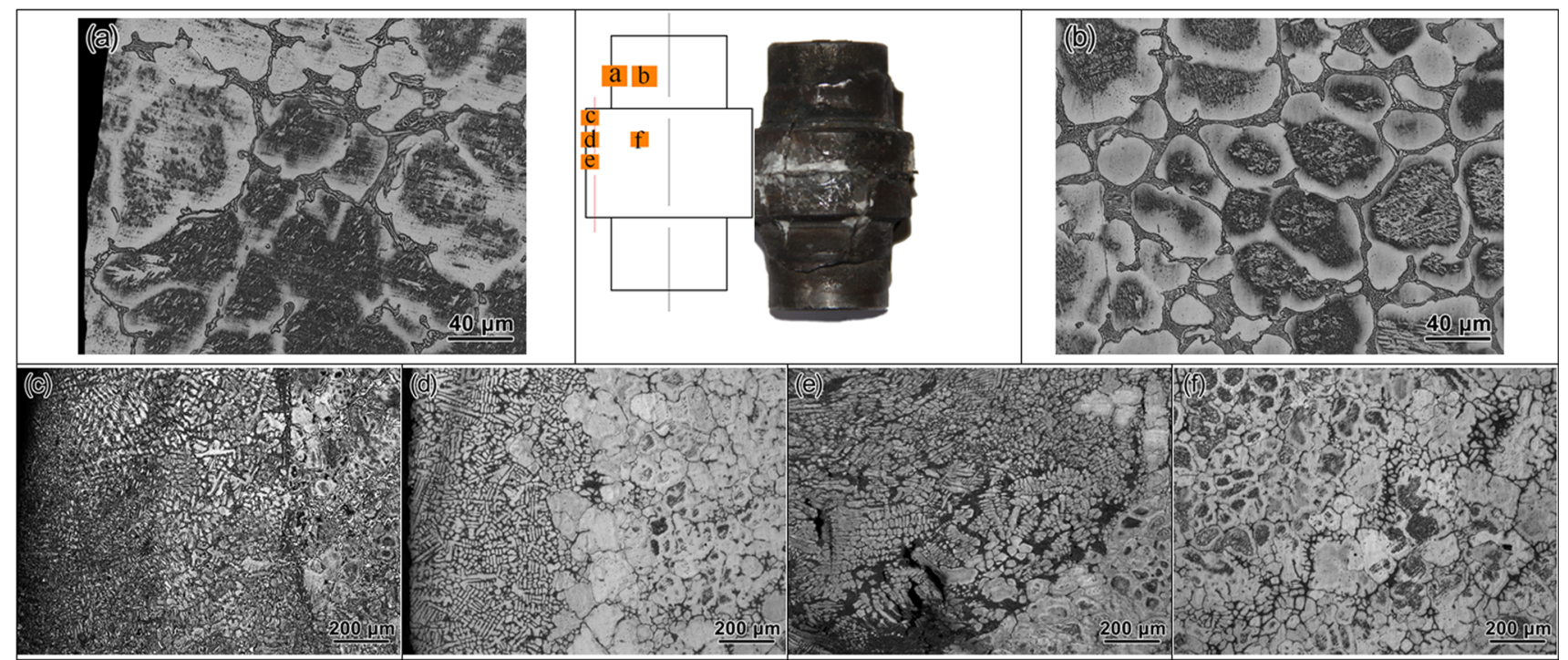

Fig. 5 Microstructure of thixoforging specimen at $1340{ }^{\circ} \mathrm{C}, 0.02 \mathrm{~s}^{-1}$, a-f are positions in the illustrated specimen, respectively 

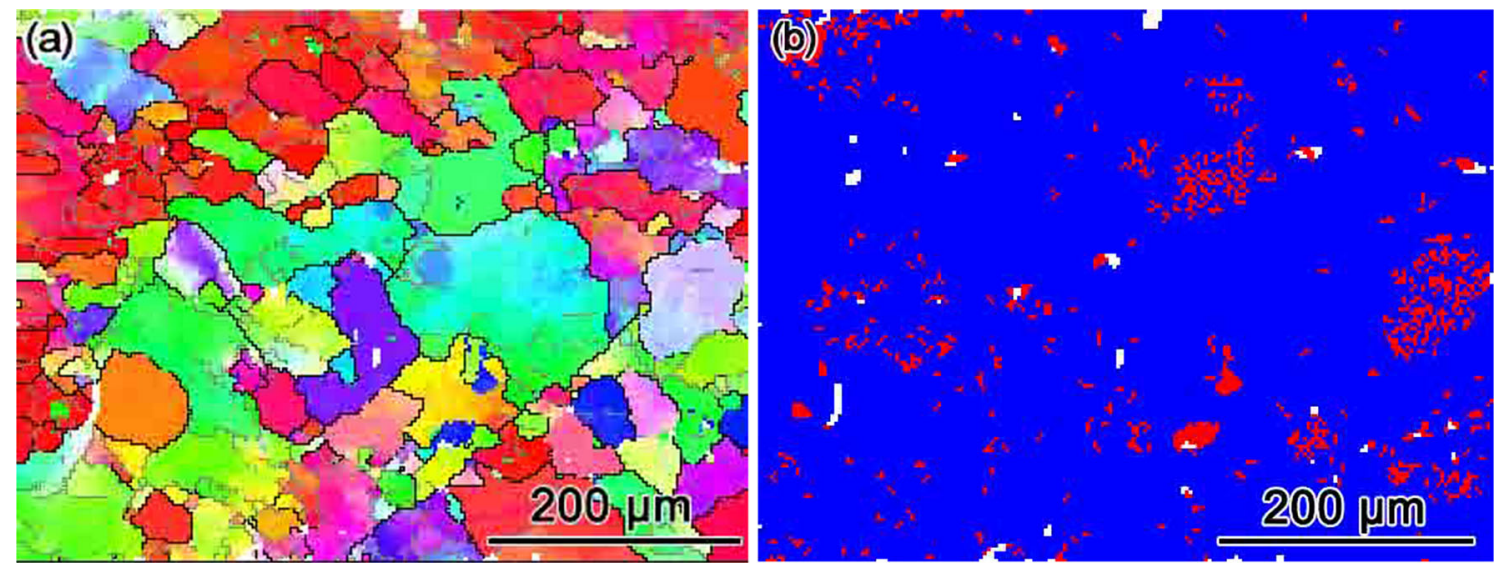

Fig. 6 EBSD mapping results of the inner area of a specimen thixoforged at $1340{ }^{\circ} \mathrm{C}, 0.02 \mathrm{~s}^{-1}$ : a IPF image; b phase image (blue: austenite; red: martensite)
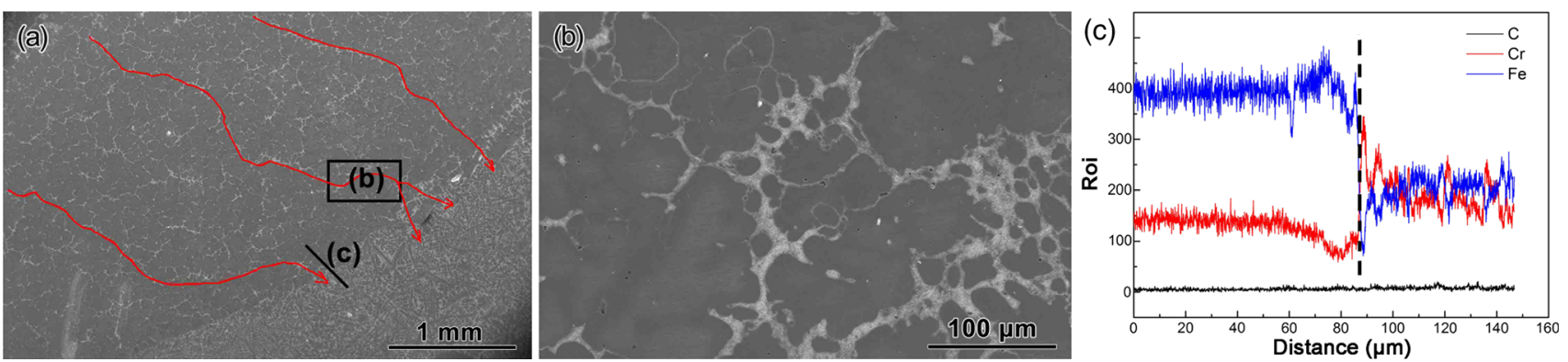

Fig. 7 Microstructures of the boundary area of a specimen thixoforged at $1340{ }^{\circ} \mathrm{C}, 0.02 \mathrm{~s}^{-1}$ : a solid/liquid boundary; b partial zoom of $\mathbf{a} ; \mathbf{c}$ EDS line scanning of line marked in a

differences exist along the radial direction. However, at the deformation region, the microstructure demonstrates different characterizations. There is a distant solid/liquid boundary at the edge of the deformation region (Fig. $5 \mathrm{c}-\mathrm{e}$ ). The liquid phase was extruded outside the boundary and formed fine dendrites. Solid particles were retained inside the boundary. Different from the semi-solid structure, solid particles were connected with each other and rare liquid films could be seen at the inner area shown in Fig. 5f. The specimen shows a variation of the microstructure along the radial direction. Wang et al. [17] suggested that molten liquid gathered and flew through several channels during thixoforging. Besides, according to EBSD measurement shown in Fig. 6, most of the solid particles inside the boundary belong to the austenite structure. The EBSD mapping results show that the volume fraction of austenite is $86.86 \%$, while that of martensite is $8.36 \%$. Traditionally, the 9 $\mathrm{Cr} 18$ steel belongs to the family of martensitic steels [19]. The conventional heat treatment (CHT) procedure for the $9 \mathrm{Cr} 18$ steel consists of quenching at $1050{ }^{\circ} \mathrm{C}$ and tempering at $200{ }^{\circ} \mathrm{C}$ for $2 \mathrm{~h}$. But at the thixoforging temperature range $\left(\sim 1300^{\circ} \mathrm{C}\right)$, there are more alloying elements which dissolve in the solid austenite particles as compared with conventional austenitization $\left(1050{ }^{\circ} \mathrm{C}\right)$. According to Puttgen et al. [20], $\mathrm{Cr}$ and $\mathrm{C}$ will lead to a decrease of the martensite starting temperature, thus stabilizing the austenite structure during cooling. This can be confirmed by the low hardness of the inner area (about 376 HV). Moreover, the liquid film is extruded outside, which prevents the formation of brittle eutectic carbide at the inner area. The average hardness of skin dendrites is about $720 \mathrm{HV}$, and the skin layer will support the wear resistance [17].

\subsubsection{Alloying Elements of Solid and Liquid Phases}

Figure 7a indicates the flow traces of liquid metal showing that there is a flow trend toward outside. During semi-solid forming, the solid particles and the liquid film demonstrate a different flow behavior [21]. The liquid film flows through the solid particles. The flow channels are shown in Fig. 7b. As shown in the EDS line scanning of the boundary area (Fig. 7c), the amount of alloying elements changes drastically. The $\mathrm{Cr}$ content increases from the 


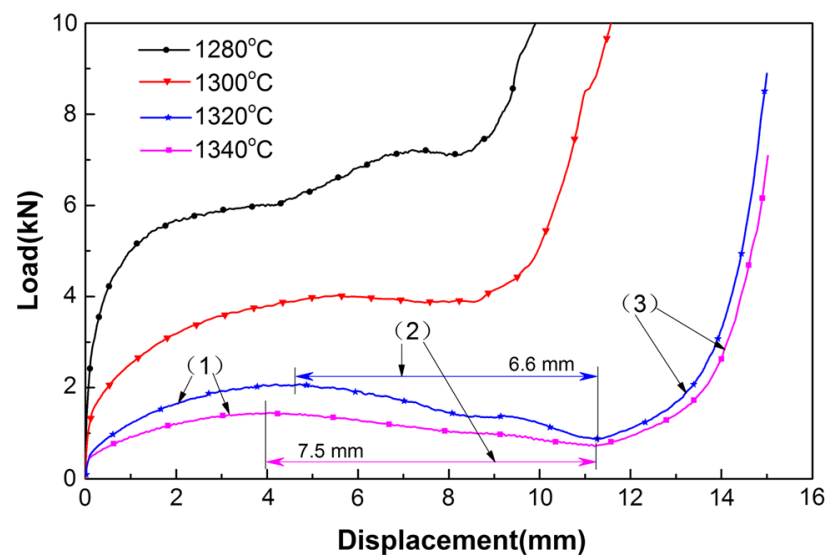

Fig. 8 Load-displacement curves during thixoforging at $0.05 \mathrm{~s}^{-1}$ at different temperatures

inner solid particles to the dendrite skin layer; while the $\mathrm{Fe}$ content shows the opposite trend.

\subsection{Solid/Liquid Flow Behavior at Different Temperatures}

Figure 8 shows the load-displacement curves of a specimen thixoforged at different temperatures (strain rate:
$0.05 \mathrm{~s}^{-1}$ ). The load signal is much higher at 1280 or $1300{ }^{\circ} \mathrm{C}$. The load soon rises beyond the upper limit of the ordinates when die closing occurs. At $1280{ }^{\circ} \mathrm{C}$, the specimen does not reach the solidus line and remains in the solid state. At $1300{ }^{\circ} \mathrm{C}$, there is only a small volume fraction of molten material. The whole liquid channel cannot be formed, so that the thixotropic behavior is not evident. The forming load remains at high level. When temperature reaches 1320 or $1340{ }^{\circ} \mathrm{C}$, the load-displacement curves show three-stage behavior. At the beginning, the load increases with the displacement due to the density of the structure (Stage 1). After reaching a peak, the load decreases gradually with the increase of displacement. The thixotropic behavior is activated at Stage 2. At the end, the load increases sharply since the specimen finishes the filling of dies. With a larger volume fraction of liquid phase, the thixotropic stage (Stage 2) under $1340{ }^{\circ} \mathrm{C}(7.5 \mathrm{~mm})$ is longer than that under $1320{ }^{\circ} \mathrm{C}(6.6 \mathrm{~mm})$. The three-stage behavior of the $9 \mathrm{Cr} 18$ steel is consistent with many previous studies of different materials during semi-solid forming [22].

Figure 9 shows the microstructure of a thixoforged specimen at the edge area under different temperatures. At $1280{ }^{\circ} \mathrm{C}$ (Fig. 9a), no macro-separation of solid/liquid
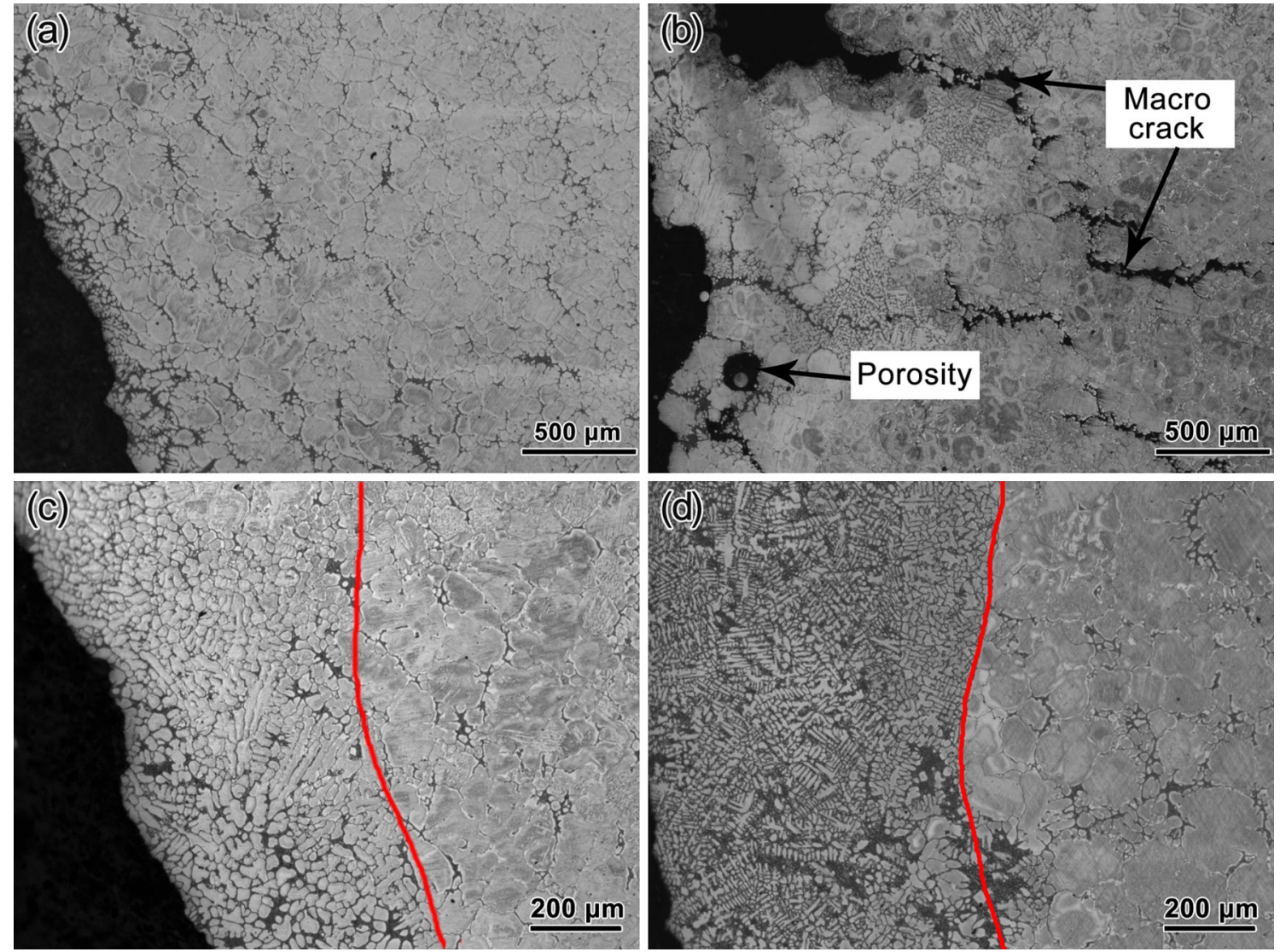

Fig. 9 Microstructure of the edge area of specimens thixoforged at $0.05 \mathrm{~s}^{-1}$ : a $1280{ }^{\circ} \mathrm{C} ; \mathbf{b} 1300{ }^{\circ} \mathrm{C} ; \mathbf{c} 1320{ }^{\circ} \mathrm{C} ; \mathbf{d} 1340{ }^{\circ} \mathrm{C}$ 

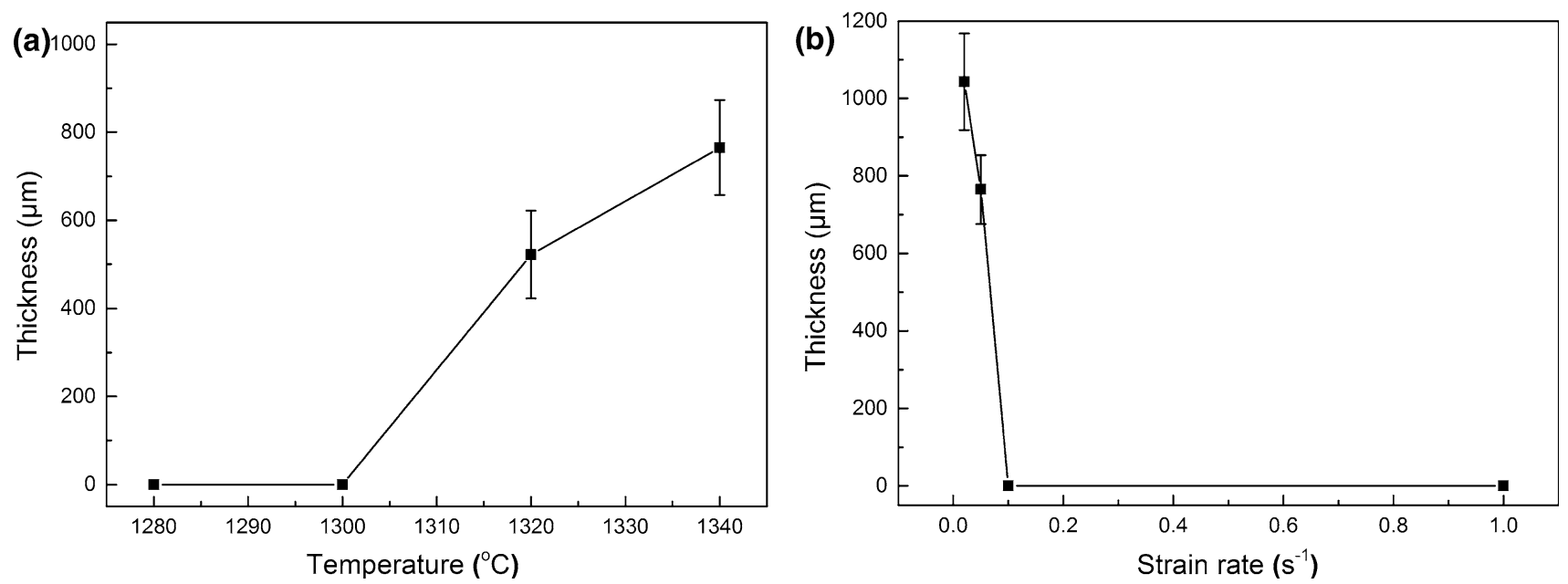

Fig. 10 Average thickness of the skin layer of specimens thixoforged at: a different temperatures under $0.05 \mathrm{~s}^{-1}$; b different strain rates under $1340{ }^{\circ} \mathrm{C}$ (average thickness: value obtained from the average of three edge areas as shown in Fig. $5 \mathrm{c}-\mathrm{e}$ )

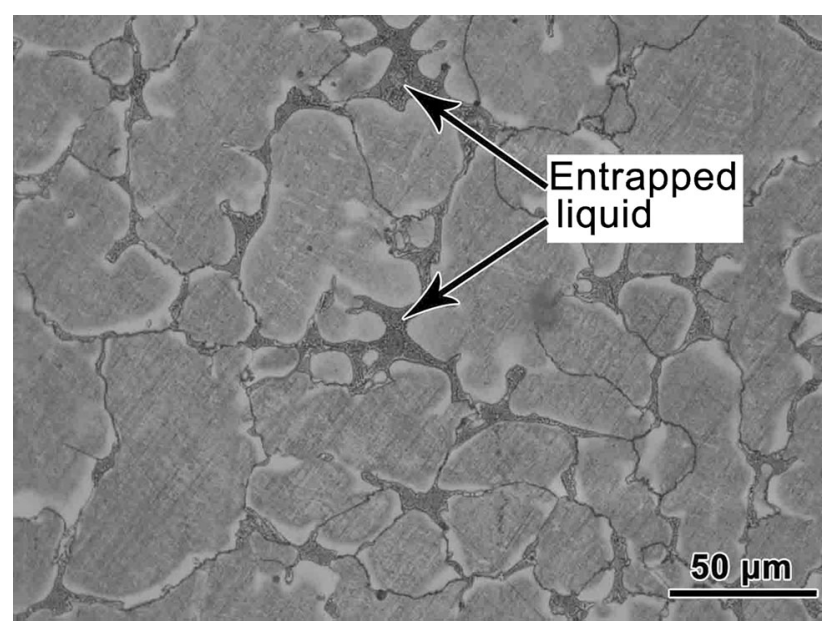

Fig. 11 Inner area of a specimen thixoforged at $1300{ }^{\circ} \mathrm{C}$

could be observed and spherical solid grains coexist with the solidified liquid film. When the temperature increases up to $1300{ }^{\circ} \mathrm{C}$ (Fig. 9b), it seems that the liquid flows outside through several channels. However, the molten liquid is not sufficient to form a skin layer. Macro-cracks and porosity can be seen at the edge area due to the solidification shrinkage of the extruded liquid. At $1320{ }^{\circ} \mathrm{C}$ (Fig. 9c) or $1340{ }^{\circ} \mathrm{C}$ (Fig. 9d), a clear solid/liquid boundary exists and a dendrite skin layer is formed. The thickness of the skin layer is of about $520 \mu \mathrm{m}$ at $1320{ }^{\circ} \mathrm{C}$. The thickness increases up to about $760 \mu \mathrm{m}$ (Fig. 10a) at $1340{ }^{\circ} \mathrm{C}$.

The heterogeneous flow phenomenon has been observed by previous studies. Kang et al. [13] proposed that the macro-solid/liquid separation leads to the formation of defects inside the specimen. Poolthong et al. [23] obtained microstructure changes of cast iron by centrifugal effect in semi-solid processing. It is commonly believed that there is a critical temperature to distinguish the homogeneous from the heterogeneous flow during semi-solid processing [24]. According to a previous study, the molten liquid flows through several channels during thixoforging. The link between the molten liquid phases is the key to the formation of flow channels. Thus, a high amount of molten liquid is required. The higher is the forming temperature, the larger is the macro-separation of solid/liquid. On the contrary, if the temperature is not high enough, the molten liquid drops cannot connect with each other. Some of them may be entrapped by the nearby solid grains and will be retained inside the sample, having no access to the surface (Fig. 11). Besides, the aggregation of molten liquid drops also occurs in some area. During cooling, they might become source of macro-cracks or inner porosity due to the solidification shrinkage.

\subsection{Solid/Liquid Flow Behavior at Different Strain Rates}

The strain rate influences the deformation time during the thixoforging process. Figure 12 shows the load-displacement curves of specimens thixoforged under different strain rates. It is evident that the curve at $1 \mathrm{~s}^{-1}$ is quite different from the other three curves. In this case, the load level is much higher and almost no thixotropic stage occurs. Conversely, all the other curves show a three-stage behavior which is similar to that discussed in Sect. 3.2. The deformation times needed for thixoforging at strain rates of $0.02,0.05,0.1,1 \mathrm{~s}^{-1}$ are of about $25,10,5,0.5 \mathrm{~s}$, 


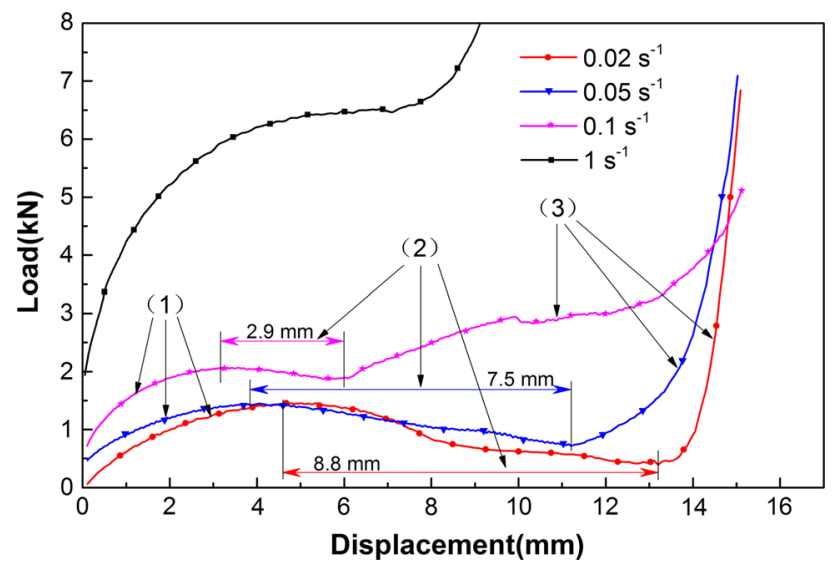

Fig. 12 Load-displacement curves during thixoforging at $1340{ }^{\circ} \mathrm{C}$ under different strain rates

respectively. The ram speed is quite fast at a strain rate of $1 \mathrm{~s}^{-1}$, and thus, the deformation time is not sufficient to activate a thixotropic behavior. Conversely, under lower strain rates, there is more time for the slide or rotation of solid particles. After the breakdown of the solid skeleton, the thixotropic behavior is activated, producing a macro- separation of solid/liquid. With the increase of the strain rate in lower condition, a smaller deformation is needed to activate the thixotropic behavior $\left(0.02 \mathrm{~s}^{-1}-4.6 \mathrm{~mm}\right.$, $0.05 \mathrm{~s}^{-1}-3.9 \mathrm{~mm}, 0.1 \mathrm{~s}^{-1}-3.0 \mathrm{~mm}$ ), i.e., the solid skeleton is broken more easily. But, as shown in Fig. 12, at the same time the length of the thixotropic stage $(8.8,7.5$ and $2.9 \mathrm{~mm}$ ) decreases. With an increase of the strain rate, the storage of the deformation energy becomes faster, so that less deformation is needed to break down the solid skeleton. However, the increase of the strain rate implies at the same time a decrease of the deformation time. Thus, the thixotropic stage shortens due to the decrease of the flowing time.

As discussed in Sect. 3.2, the thixotropic stage has a direct influence on the microstructure of thixoforged specimens. During the thixotropic stage, a slide or rotation of the solid particles, and a flow of the liquid film both occur [25]. The increase of the strain rate leads to the shortening of the thixotropic stage, so that at the same time the amount of liquid extruded outside is reduced. As shown in Fig. 13, the microstructures in edge area of specimen thixoforged at 0.02 and $0.05 \mathrm{~s}^{-1}$ demonstrate a whole dendrite skin layer. Thickness of skin layer thixoforged at
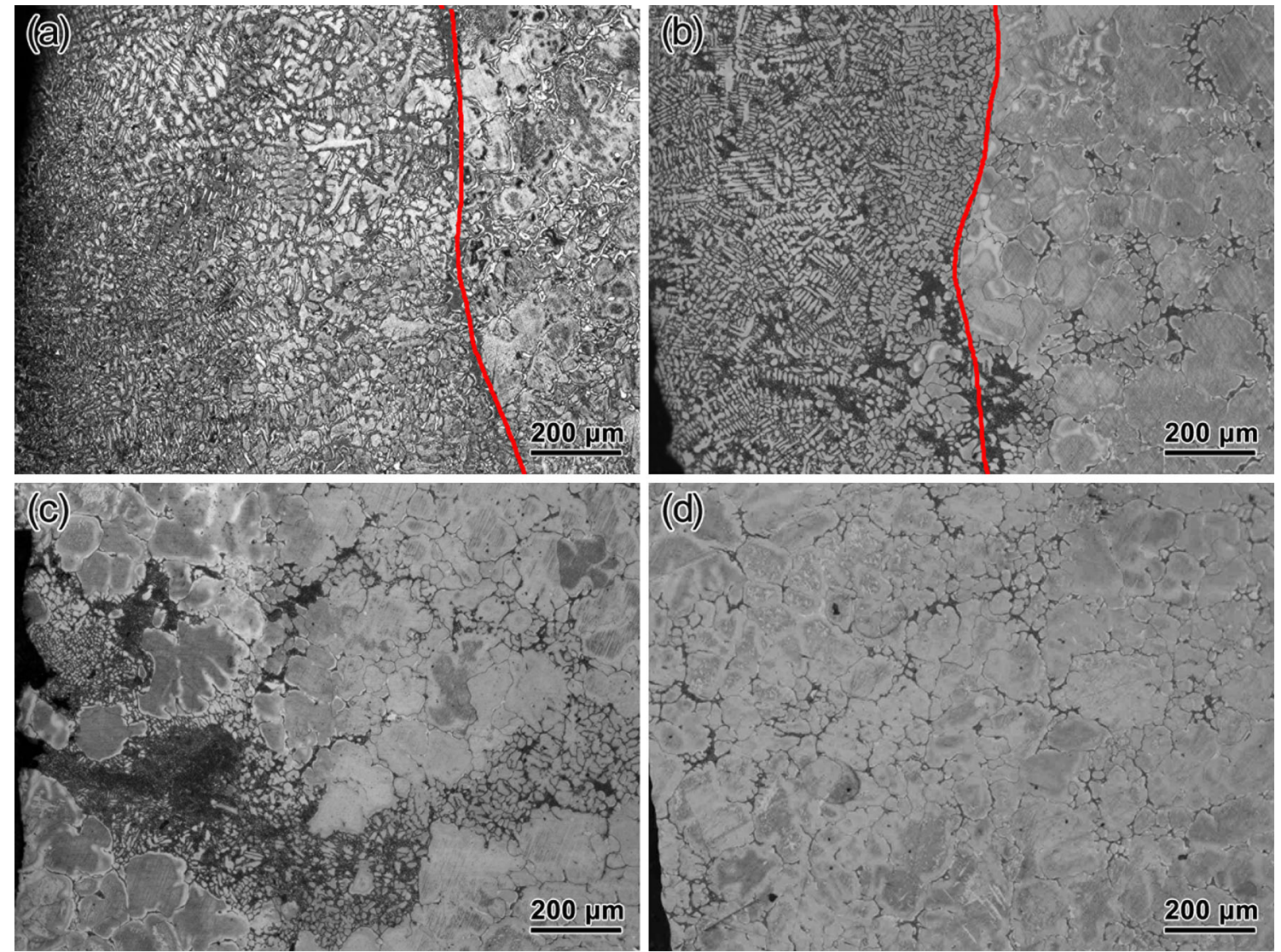

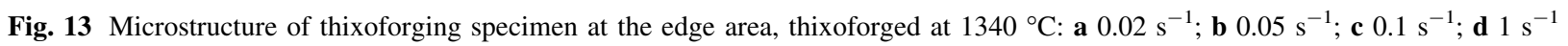


$0.02 \mathrm{~s}^{-1}$ is over $1000 \mu \mathrm{m}$ (Fig. 10b), while microstructures at 0.1 and $1 \mathrm{~s}^{-1}$ only show separation of solid/liquid and no whole skin layer is formed.

\section{Conclusions}

In this study, a $9 \mathrm{Cr} 18$ thixoforging test was conducted in a designed setup. The effects of the forming temperature and the strain rate on the microstructure were investigated. The main conclusions are summarized as follows:

1. The 9Cr18 thixoforged specimen can demonstrate functional gradient properties. Changes of microstructure along the radial direction could be obtained. Solid austenite was retained after fast cooling, and the liquid film enriched in alloying elements was extruded outside to form a dendrite skin layer.

2. As temperature increases, more molten liquid will form during thixoforging. A heterogeneous flow phenomenon is activated as a free liquid channel is formed. Macro-separation of solid and liquid phases is critical for the formation of functional gradient properties.

3. The strain rate affects the thixotropic properties by influencing the deformation time of thixoforging. During lower strain rate, there is more time for the flow of liquid metal, which is the key to the extension of the thixotropic stage.

4. High temperatures (typically $\geq 1320{ }^{\circ} \mathrm{C}$ ) and low strain rates (typically $\leq 0.05 \mathrm{~s}^{-1}$ ) will contribute to the formation of a full skin layer, which is the key factor to produce a tough center and a hard surface for the designed multi-diameter specimen.

Acknowledgement The research was supported by the National Natural Science Foundation of China (No. 51175036).
[2] R.B. Song, Y.L. Kang, A.M. Zhao, J. Mater. Proc. Technol. 198, 291 (2008)

[3] M. Kiuchi, R. Kopp, CIRP Ann.-Manuf. Technol. 51, 653 (2002)

[4] Y. Meng, S. Sugiyama, M. Soltanpour, J. Yanagimoto, J. Mater. Process. Technol. 213, 426 (2013)

[5] S.P. Midson, Solid State Phenoma 217-218, 487 (2014)

[6] R.G. Guan, Y.F. Shen, Z.Y. Zhao, R.D.K. Misra, Sci. Rep. 6, 23154 (2016)

[7] Y. Zhang, G.H. Wu, W.C. Liu, L. Zhang, S. Pang, W.J. Ding, Mater. Des. 67, 1 (2015)

[8] A. Bolouri, J.W. Bae, C.G. Kang, Mater. Sci. Eng., A 562, 1 (2013)

[9] J. Dutkiewicz, Ł. Rogal, K. Sołek, A. Mitura, Int. J. Mater. Forum 2, 753 (2009)

[10] E. Becker, V. Favier, R. Bigot, P. Cezard, L. Langlois, J. Mater. Proc. Technol. 210, 1482 (2010)

[11] G.C. Gu, R. Pesci, L. Langlois, E. Becker, R. Bigot, M.X. Guo, Acta Mater. 66, 118 (2014)

[12] S. Muenstermann, K. Uibel, T. Tonnesen, R. Telle, J. Mater. Process. Technol. 209, 3640 (2009)

[13] C.G. Kang, J.S. Choi, K.H. Kim, J. Mater. Process. Technol. 88, 159 (1999)

[14] X. Luo, Y.Z. Liu, B. Wang, Acta Metall. Sin. (Engl. Lett.) 28, 1305 (2015)

[15] M. Payandeh, A.E.W. Jarfors, M. Wessen, Solid State Phenoma 217-218, 67 (2014)

[16] C.Q. Zhao, R.B. Song, Mater. Des. 59, 502 (2014)

[17] Y.J. Wang, R.B. Song, Y.P. Li, Mater. Des. 86, 41 (2015)

[18] G.C. Gu, R. Pesci, L. Langlois, E. Becker, R. Bigot, J. Mater. Process. Technol. 216, 178 (2015)

[19] J.R. Yang, T.H. Yu, C.H. Wang, Mater. Sci. Eng., A 438-440, 276 (2006)

[20] W. Puttgen, B. Hallstedt, W. Bleck, P.J. Uggowitzer, Acta Mater. 55, 1033 (2007)

[21] J. Fonseca, C.O. Sullivan, T. Nagira, H. Yasuda, C.M. Gourlay, Acta Mater. 61, 4169 (2013)

[22] T.Y. Liu, H.V. Atkinson, P. Kapranos, D.H. Kirkwood, S.C. Hogg, Metall. Trans. A 34, 1545 (2003)

[23] N. Poolthong, P. Qui, H. Nomura, Sci. Technol. Adv. Mater. 4, 481 (2003)

[24] R.G. Guan, Z.Y. Zhao, X. Wang, C.G. Dai, C.M. Liu, Acta Metall. Sin. (Engl. Lett.) 26, 293 (2013)

[25] K. Hu, A.B. Phillion, D.M. Maijer, S.L. Cockfroft, Scr. Mater. 60, 427 (2009)

\section{References}

[1] M.C. Flemings, Metall. Trans. A 22, 957 (1991) 